\title{
Um olhar estrangeiro para a escola brasileira Carl Ernest Zeuner desenhando quadros murais (Revista do Ensino/RS, 1963-1969)
}

\author{
A foreign look at brazilian schools \\ Carl Ernest Zeuner drawing wall charts \\ (Revista do Ensino/RS, 1963-1969) \\ Una mirada extranjera para la escuela brasileña \\ Carl Ernest Zeuner dibujando cuadros murales \\ (Revista do Ensino/RS, 1963-1969) \\ Maria Helena Camara Bastos \\ Universidade Federal do Rio Grande Sul (Brasil) \\ http://orcid.org/0000-0003-0246-9286 \\ http://lattes.cnpq.br/4190797203813239 \\ mhbastos1950@gmail.com
}

\section{RESUMO}

Carl Ernest Zeuner nasceu em Zwickau, nas proximidades da fronteira alemã com a República Tcheca, em 13 de agosto de 1895. Em 1922 veio para o Brasil, radicando-se em Porto Alegre/RS. Foi pintor, desenhista e ilustrador, atuando na Livraria e Editora Globo. Na década de 1960, colaborou com a Revista do Ensino/RS (1951-1978) desenhando uma série de quadros murais. $\mathrm{O}$ presente artigo tem por objetivo analisar os suplementos didáticos ou quadros murais, também denominados "Material Didático para as Classes do Curso Primário". Abordando os quadros murais como expressão da liturgia do universo escolar e educacional de um determinado período da escola brasileira e rio-grandense, a partir da ideia que expressam uma linguagem feita de imagens, o estudo toma como objeto de análise os quadros pintados por Zeuner, em número de 61, no período de 1963 a 1969.

Palavras-chaves: Cultura escolar; Quadros murais; Dispositivo pedagógico. 


\begin{abstract}
Carl Ernest Zeuner was born in Zwickau, in the neighborhoods of the border between Germany and the Czech Republic, on August 13, 1895. In 1922, he came to Brazil and settled in Porto Alegre/RS. He was a painter, drawer and illustrator, and worked at Globo Bookstore and Publishing House. In the 1960s, he collaborated with Revista do Ensino Magazine/RS (1951-1978), drawing a series of wall charts. This paper aims at analyzing his didactic supplies or wall charts, also called "Didactic Material for Primary Course Classrooms". Approaching wall charts as an expression of the liturgy of Brazil's and Rio Grande do Sul's educational and school universe in that period, and considering that they express a certain language through images, the study analyzes 61 wall charts painted by Zeuner between 1963 and 1969.
\end{abstract}

Keywords: School culture; Wall charts; Pedagogical device.

\title{
RESUMEN
}

Carl Ernest Zeuner nació en Zwickau, en las proximidades de la frontera alemana con la República Checa, el 13 de agosto de 1895. En 1922 llegó a Brasil, radicándose en Porto Alegre/RS. Fue pintor, dibujante e ilustrador, actuando en la Librería y Editora Globo. En la década de 1960, colaboró con la Revista do Ensino/RS (1951-1978) dibujando una serie de cuadros murales. El presente artículo tiene por objetivo analizar los suplementos didácticos o cuadros murales, también denominados "Material Didáctico para las Clases del Curso Primario". Tomando como objeto de análisis los cuadros pintados por Zeuner -61 en total-, en el período de 1963 a 1969, se entienden los cuadros murales como expresiones de la liturgia del universo escolar y educativo de un determinado período de la escuela brasileña y río-grandense, basándose en la idea de que estos expresan un lenguaje hecho de imágenes.

Palabras claves: Cultura escolar; Cuadros Murales; Dispositivo pedagógico. 
As imagens potencializam as palavras. Gabriel García Márquez ([1997] 2011, p. 101)

\section{INTRODUÇÃO}

A imagem nas instituições escolares é amplamente reconhecida por sua importância cultural e social, presente desde a educação infantil à Universidade, não somente como auxiliar ou suporte do ensino, mas também objeto de estudos (RENONCIAT, 2011, p. 5). É uma proposta ou protocolo de leitura, sugerindo ao leitor a compreensão do texto e do seu significado. Neste papel, "pode constituir-se num lugar de memória que cristaliza, numa representação única, uma história, uma propaganda, um ensinamento, ou ser então construída como a figura moral, simbólica, analógica, que fornece o sentido global do texto, que uma leitura descontínua e vagabunda poderia fazer perder" (CHARTIER, 1998, p.15). Para o autor, as imagens não são meras ilustrações inseridas no espaço escolar, há sempre uma motivação, ainda que inconsciente, para seu uso, para como e onde será utilizada.

A produção iconográfica com objetivos pedagógicos é uma ferramenta útil para a representação do real, permitindo analisar tanto a imagem para ver como a imagem dada $a$ ver. A imagem não apenas complementa o texto, como, ainda, é protagonista da mensagem escrita, ao trazer à escola o mundo tal qual esse deve ser percebido. As imagens, representando tanto as coisas visíveis como as invisíveis, são textos dados ler, conduzindo o aluno a uma atividade interpretativa do real a partir da associação de ideias (CHAMEL, 2004, p.52 e 72).

O método intuitivo, que parte dos fatos para chegar às ideias, tem por princípio que todo o conhecimento resulta dos sentidos, do fato de ver e tocar os objetos, o que paulatinamente permite ao estudante construir a ideia abstrata, a comparar, a generalizar, a racionalizar sem a necessidade de exemplos materiais (RENONCIAT, 2011, p. 79). Dessa forma, quando a observação direta não é possível, os quadros murais são os dispositivos que cumprem essa função de representação da realidade.

A partir dessas considerações, o presente artigo tem por objetivo apresentar a Revista do Ensino/RS, especialmente os suplementos didáticos ou quadros murais, encarte mensal destacável, também denominados "Material Didático para as Classes do Curso Primário" (BASTOS, LEMOS, BUSNELLO, 2007).

Abordando os quadros murais como expressão da liturgia do universo escolar e educacional de um determinado período da escola brasileira e rio-grandense, o estudo toma como objeto de análise os quadros murais desenhados pelo imigrante austríaco Carl Ernest Zeuner (1895-1967) ${ }^{1}$, em número de 61, desenhados em têmpera sobre papel, para integrar os suplementos didáticos da Revista do Ensino/RS, no período de 1963 a 1969, os quais fazem parte do acervo do Museu de Arte do Rio Grande do Sul Aldo Malagoli (1982)/MARGS e estão digitalizados².

Quanto à metodologia de análise das gravuras de Zeuner e dos quadros murais, nos deteremos especialmente no que objetivavam como dispositivo pedagógico na escola primária da década de 1960. Dubois (2004) considera que não existe um método para analisar imagens. Parte da ideia de que "a imagem que temos diante de nós é ao mesmo tempo um objeto de cultura e um objeto por natureza. É um objeto de cultura sobre o qual

\footnotetext{
${ }^{1}$ Sabendo que o desenhista tinha integrado à equipe da Revista do Ensino/RS, somente em 2016, quando da exposição "A Modernidade Impressa", com a curadoria de Paula Ramos, que tomei contato com dois quadros murais do autor, em exposição. Em contato com a curadora, soube que o acervo se encontrava no Margs. Aproveito para agradecer a preciosa indicação.

${ }^{2}$ Acervo Ernest Zeuner http://www.margs.rs.gov.br/catalogo-de-obras/E/16818/
} 
existe um enorme saber, e é preciso dominar esse saber para abordar as imagens. (...) A imagem é também algo em si, que tem um poder que lhe é próprio e que não se origina do saber constituído a seu respeito" (In: FERREIRA; KORNIS, 2004, p. 152-53).

\section{A Revista do Ensino/RS (1951-1978): O ensino pela imagem³}

A Revista do Ensino começa a ser editada em setembro de 1951, como iniciativa das professoras primárias. Com o apoio institucional da Secretaria de Educação e Cultura/RS, em 11 de dezembro de 1956 a revista passa a ser uma publicação oficial. Sob a supervisão técnica do Centro de Pesquisas e Orientações Educacionais - CPOE/RS (1943-1971)4, divulga as orientações pedagógicas desse centro de pesquisa ${ }^{5}$. Com a intenção de não só "preencher o lugar vazio junto ao professor primário, estagiário ou não", como também de aspirar a que a educadora jovem e idealista encontrasse nas suas páginas a solução para "resolver os árduos, porém sublimes, problemas de seu mister". Nesse sentido, a revista volta-se preponderantemente a orientar a professora primária rio-grandense, divulgando diretrizes técnico-pedagógicas, material didático e legislação relativa ao ensino.

A iconografia se fez presente na Revista do Ensino/RS de três formas: as capas, que reproduzem fotos do cotidiano escolar e/ou composições gráficas elaboradas pela equipe editorial; as contracapas, que são utilizadas como espaço para material didático e de propaganda; e os suplementos didáticos ou quadros murais, encarte mensal destacável. O periódico mantinha uma equipe permanente para planejamento e ilustração. Muitos desses profissionais permaneceram ao longo de toda a publicação, sendo responsáveis pelo acabamento gráfico e pelo equilíbrio conceitual e estético do periódico.

$\mathrm{O}$ intenso estímulo à iconografia em sala de aula reflete a materialização do discurso didático-pedagógico do CPOE/RS, tendo por fundamento a escola renovada "a implantação dos métodos ativos; a centralidade da criança no processo de aprendizagem; a escola como espaço de exercício da criatividade; o desenvolvimento da autodisciplina, da liberdade individual, da consciência moral dos educandos, desenvolvimento do espírito crítico; compreensão da realidade". Essas foram as metas do Centro visando acompanhar a "civilização em mudança" e os desafios da vida em uma sociedade democrática (GARCIA, PERES, 2002, p102).

Os quadros, para uso em sala de aula, são desenhos coloridos, em tamanho de 44 $\mathrm{cm}$ por $37 \mathrm{~cm}$, com perfeito acabamento gráfico, que contemplam temas específicos, organizados em séries de gravuras: zoologia, linguagem, histórica ${ }^{6}$. A partir de 1960, a equipe editorial modifica a apresentação gráfica do material didático suplementar. $\mathrm{O}$ tamanho passa a ser bem maior $(80 \mathrm{~cm} \times 107 \mathrm{~cm})$, traz as orientações ao professor no próprio suplemento (atrás), apresenta os temas das disciplinas do currículo primário linguagem, matemática, ciências naturais, história e geografia - em um único quadro, com legendas.

\footnotetext{
${ }^{3}$ Esta seção retoma vários estudos que já foram publicados tendo como objeto a Revista do Ensino/RS, para inserir o leitor no foco do artigo (BASTOS, 1997; BASTOS, 2005; BASTOS, BUSNELLO, 2004; BASTOS, LEMOS, BUSNELLO, 2007).

${ }^{4}$ Sobre o CPOE/RS, ver Quadros (2005); Peres (2000).

5 O CPOE/RS, além de editar a Revista do Ensino para professores, publica a revista infantil Cacique, destinada aos alunos (BASTOS, 1994), e o Boletim do Centro de Pesquisas e Orientações Educacionais/CPOE, publicado a cada dois anos, de 1947 a 1966, com as orientações, pesquisas, legislação, bibliografia, provas escolares.

${ }^{6}$ Bittencourt (2002, p.71) afirma que as vinhetas ou legendas colocadas em cada ilustração indicavam o que o aluno deveria observar e reforçava a ideia contida no texto.
} 
Em 1965, com a mudança de direção da revista, também ocorrem mudanças no projeto editorial e gráfico. Algumas capas passam a ser desenhadas e as orientações didático-pedagógicas do material didático suplementar passam a serem designadas "Como aproveitar o suplemento", abordando diferentes temas das disciplinas do currículo da escola primária.

Essa seção apresenta sempre a equipe responsável pela orientação e layout, pelo planejamento e pelos desenhos. Para o suplemento $O$ Ano em Estações (nº 108, 1966): a responsável pela orientação e layout é a professora Maria Madalena Lutzenberger, o planejamento é das professoras Maria Aparecida Grendene e Ercila T. Ambros, e o desenho de Carl Ernest Zeuner e Elsy Pires Ferreira. Essa distribuição das tarefas expressa a preocupação da equipe editorial tanto com a questão didático-pedagógico como iconográfica.

A iconografia foi disponibilizada para todas as disciplinas do currículo da escola primária, assim como as orientações para sua exploração em sala de aula, para confecção de quadros murais, para a utilização de recursos audiovisuais. O índice cumulativo por assunto da revista elege gravuras e estampas, como uma categoria de classificação do conteúdo, subdividida em: nossas capas, calendário escolar, ciências naturais, ciências sociais, desenho, geografia do Brasil, geografia exterior, higiene, história do Brasil, linguagem, música.

De uma maneira geral, as sugestões didático-pedagógicas da Revista do Ensino limitam-se a orientar uma leitura inicial e interna da própria ilustração, para a identificação do seu conteúdo. A sequência de observações, descrições e narrações é muito importante, pois cria textos - orais e/ou escritos, que permitem ao aluno estabelecer relações com outros contextos e experiências. No entanto, é necessária ainda uma leitura externa, para permitir identificar outros referenciais, que caracterizam a imagem como objeto - como e por que foi produzida, para que e para quem se fez, quando foi realizada -, permitindo uma leitura mais crítica e analítica (BITTENCOURT, 2002, p.88).

\section{OS QUADROS MURAIS DE CARL ERNEST ZEUNER (1963-1969)}

Figura 1 e 2: Auto-retrato com 15 anos Auto-retrato (1940)
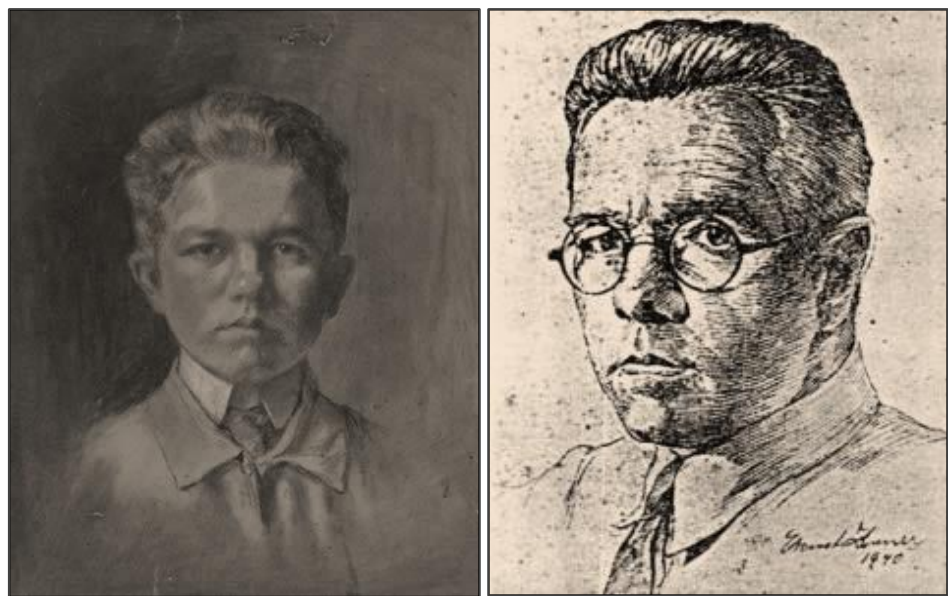

Fonte: Acervo do MARGS

Karl Ernest Zeuner nasceu em Zwickau, nas proximidades da fronteira alemã com a República Tcheca, em 13 de agosto de 1895, formou-se na Academia de Artes Gráficas de Leipzig/Alemanha. Em 1922 veio para o Brasil, radicando-se em Porto Alegre/RS. Foi pintor, desenhista e ilustrador, atuando por quatro décadas na Livraria e 
Editora Globo ${ }^{7}$, como responsável pelo atelier de artes gráficas, especificadamente a seção de desenho e planejamento gráfico. Foi ilustrador da Revista do Globo ${ }^{8}$, de numerosos livros. Também desenhou embalagens, propagandas, selos de impostos, calendários e enciclopédias, cartões. Formou muitos artistas gráficos do Rio Grande do Sul. Faleceu em Porto Alegre em 1967, aos 72 anos ${ }^{9}$.

A partir da ideia de que os quadros murais de Carl Ernest Zeuner na Revista do Ensino/RS expressam uma linguagem feita de imagens, analisamos as gravuras conservados no MARGS. De um conjunto de 60 ilustrações feitas para o periódico, 30 foram extraviadas e as outras a SEC/RS doou para o MARGS (GOMES, 2001, p.88). Posteriormente, acreditase que houve mais doações, totalizado 61 imagens, sendo 8 sem títulos ${ }^{10}$. Também analisamos o acervo do HISALES/História da Alfabetização, leitura e escrita e dos livros escolares da Faculdade de Educação da Universidade Federal de Pelotas/RS, que recebeu de doação, em abril de 2017, um conjunto expressivo de quadros murais encartados na Revista do Ensino/RS ${ }^{11}$. Os acervos permitiram verificar o que foi realmente publicado e a composição dada com os desenhos de Zeuner.

As datas de 1963 a 1969, segundo a identificação do Margs, decorrem de que muitas gravuras foram publicadas, mesmo depois de sua morte (1967), até a década de 1970. De 1965 (RE/RS, nº0) a 1966 (RE/RS n¹10), Zeuner está presente sempre nos créditos dos Suplementos Didáticos. Seu nome aparecerá depois somente no número 124 de 1969, com o quadro "A vida brasileira na Época Colonial I". Esses dados permitem pensar que outros quadros foram pintados, além daqueles localizados.

Gomes $(2001,85)$ assinala que Zeuner fazia seus trabalhos tanto em gauche (tinta opaca, em que entra goma-arábica dissolvida em água e mel ou alguma substância semelhante) como em aquarela. Destaca os originais pintados em gauche - as ilustrações da série "Aspectos da Vida no Brasil", criadas para a Revista do Ensino/RS e impressas em offset nas oficinas da Globo ${ }^{12}$. Foram sessenta motivos pintados, das diversas regiões do Brasil, para serem utilizados por professores e alunos, como "cenários" didáticos em sala de aula.

Sobre "Aspectos da vida no Brasil”, Nelson Boeira Fäedrich (1983) escreve: "a arte que Zeuner colocou nestas têmperas transcendem ao simples objetivo de se transformarem em material didático. Em original de apenas $32 \times 12 \mathrm{~cm}$, o artista mostrou mais uma vez um conhecimento técnico impressionante. Alguns trabalhos, pelo detalhismo que apresentam, parecem obra de miniaturista" (apud GOMES, 2001, p.88). As gravuras foram realizadas em papel com tamanho reduzido $(32 \times 12 \mathrm{~cm})$, mas impressas em tamanho grande $(80 \mathrm{~cm} \mathrm{x}$ $107 \mathrm{~cm}$ ), no qual era efetuada quatro dobraduras para ser inserido no periódico, cujo tamanho era $29 \mathrm{~cm} \times 22 \mathrm{~cm}$, padrão de uma folha A4.

O conjunto "Aspectos da Vida no Brasil" está dividido em várias séries, muitas das quais estão incompletas:

\footnotetext{
${ }^{7}$ Sobre a Livraria e Editora Globo, ver Torrensini (1998), Ramos (2016).

8 A Revista do Globo foi um periódico ilustrado brasileiro editado quinzenalmente pela Livraria do Globo, em Porto Alegre, entre 1929 e 1967. Sobre ver Hallewell (2005).

${ }^{9}$ Sobre ver Gomes (2001).

${ }^{10}$ Cabe registrar que a coleção completa da Revista do Ensino/RS está conservada em inúmeras bibliotecas do Estado. A maioria está encadernada. No entanto, os suplementos didáticos foram descartados e hoje são de difícil localização, o que dá à coleção de Zeuner um valor inestimável.

${ }^{11}$ Agradeço à professora Dr ${ }^{\mathrm{a}}$ Eliane T. Peres, coordenadora do HISALES, a oportunidade de examinar esse acervo, pessoalmente.

12 No entanto, constatamos que até o suplemento didático de número 104 (1964) foram publicados pela Editora Globo. Os demais são editados pela Editora Monumento, que assume o periódico de 1965 a 1968. Sobre as Editoras da Revista do Ensino/RS, ver Bastos (1997).
} 
- A vida na cidade (15 gravuras): A Fábrica. Os operários; Aspecto Sociocultural da comunidade; Aspectos característicos de uma cidade; Aspectos centrais de uma cidade; Luz e Água. Usina Hidráulica; Meios de comunicação telefone, televisão, rádio, correio (Pequena História da Comunicações (suplemento $\mathrm{n}^{\circ}$ 104, 1964; Meios de Transporte (suplemento $\mathrm{n}^{\circ} 137,1971$ ); O Porto; Recreação Infantil: o Parque; Supermercado - as compras; Serviço de Salvamento - homens rã; Visão geral de uma cidade; imagem sem título grandes edifícios; servidores da comunidade (Profissões a serviço da Comunidade I, suplemento $\mathrm{n}^{\circ} 119,1968$; Profissões a serviço da Comunidade II, $\left.\mathrm{n}^{\circ} 122,1969\right)$.

- Principais comemorações do ano na cidade (8 gravuras): Páscoa; Dia da Árvore; Dia do Trabalho; Dia das Mães; Festa Junina; Dia dos Pais; Semana da Pátria; Natal (suplemento no 110,$1966 ; n^{\circ} 114,1967$ );

- Trabalho Humano, Indústria brasileira (1 gravura): Aspectos da zona industrial de uma cidade (suplemento $\mathrm{n}^{\circ} 100,1965 ; \mathrm{n}^{\circ} 102,1965$; suplemento $\mathrm{n}^{\circ} 108,1966$; suplemento $\left.\mathrm{n}^{\circ} 109,1966\right)$

- A Vida no Litoral (10 gravuras): A pesca no sul; A praia; Dunas; Escarpas; Ilha e Farol; O peixe e seus produtos; Peixeiro no Nordeste; A pesca no nordeste; Pescadores; Salinas (suplemento 29, $\mathrm{n}^{\circ}$ 81, 1962; $\mathrm{n}^{\circ} 39$, set. 1963); suplemento Mar, belo mar selvagem (n¹66, 1977);

- A Vida no campo (7 gravuras): Colheita do café; Matança do gado e charqueada; Meios de Transporte; Plantação e colheita do algodão; Plantação e colheita do café; Plantação e colheita do trigo; Vaquejada (suplemento $\mathrm{n}^{\mathbf{0}} 30$, 1959).

- A Vida na Serra (11 gravuras): Águas Minerais; Animais de carga; Extração de ouro e de pedras preciosas; Meios de comunicação; Meios de Transporte; Minas de Carvão e pedreira; Potências hidráulicas; Usina hidrelétrica; Veículos diversos; Viticultura; Madeiras.

- A Vida na Mata (9 gravuras): Meios de Transporte Terrestre; Meios de Transporte Fluviais - madeira; Tipos de embarcação da Bacia Amazônica; Vitória Régia; O Seringueiro e os produtos da extração; O Guaraná; A extração da Carnaúba; Tipos humanos.

- Tipos humanos (2 gravuras sem título):

Sydia Sant'Ana Bopp, no artigo "As gravuras no ensino de linguagem" ( $\mathrm{n}^{\mathrm{o}} 55$, set. 1958, p.32), traz uma classificação em três tipos: gravuras de sentido completo, quando a criança tem apenas de narrar, contar o que a figura apresenta; gravuras de sentido incompleto, quando apresentam uma parte do fato, deixando o resto para a imaginação da criança; gravuras que ilustram fatos, cuja finalidade consiste em alargar as experiências infantis, especialmente as de natureza histórica e geográfica. Nesse último tipo, temos praticamente toda a série produzida por Ernest Zeuner.

Cruzando a informação do acervo do MARGS com o Índice Cumulativo da Revista do Ensino, as referências dos Suplementos do Mês, e o acervo do Hisales, constata-se que muitos quadros do conjunto foram publicados. No entanto, não consta do acervo do Margs algumas produções das quais o desenho era de autoria de Carl Ernest Zeuner e Elsy Pires Ferreira. Por exemplo, O Ano em Estações (nº108, 1966), é possível perceber as quatro imagens mais significativas da temática são de Zeuner. Acredita-se que a participação de Ferreira se restringia à composição do mural e a inserção de pequenas figuras humanas para compor os espaços vazios. 
Figura 3: Suplemento didático “O ano em Estações”.

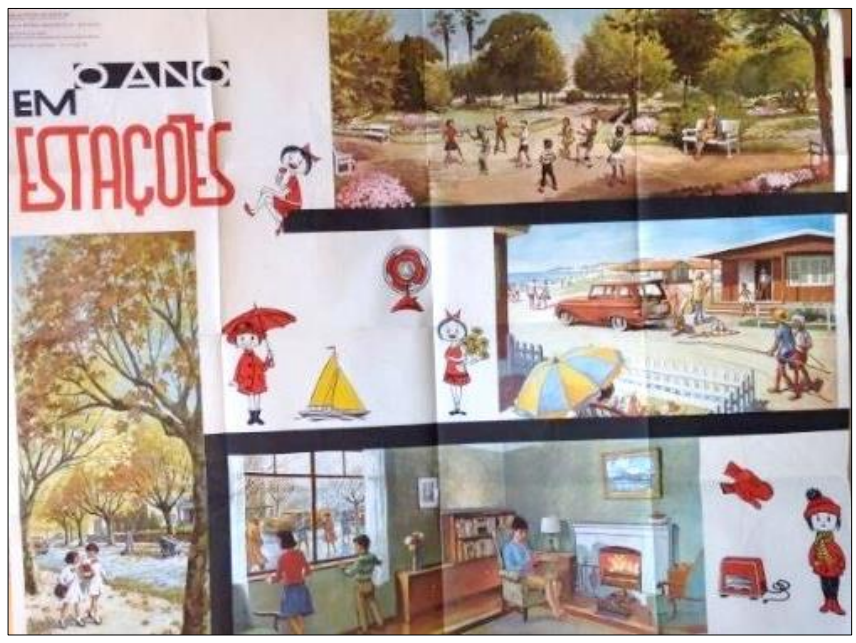

Fonte: Revista do Ensino/RS, n.108, 1966, p.64.

Zeuner também participou com desenhos no suplemento "A vida brasileira na época colonial I”, juntamente com Nilza Grau Haertel ${ }^{13}$, em que a orientação destaca

(...) apresentamos como destaque visões de conjunto sobre os dois núcleos de população da época: a cidade - onde o comércio se evidencia, o que acarreta um tipo de organização social - e o engenho, onde a tônica principal é a produção e que reúne em torno de si outro tipo de organização social, buscando manter-se autônomo com relação à cidade. Como complemento, mostramos detalhes arquitetônicos, utensílios e objetos de decoração de interiores usados no Brasil Colônia e que servirão para levar o aluno a conhecer as características daquela fase, como para que perceba, nas atuais tendências da arquitetura e decoração brasileiras, a influência do estilo colonial. (Revista do Ensino/RS, nº124, 1969, p.64)

Na figura 4, abaixo, observa-se que o quadro mural foi composto por treze gravuras, das quais somente as quatro coloridas permitem identificar como de autoria de Zeuner.

Figura 4: Suplemento didático: “A vida brasileira na época colonial I”.

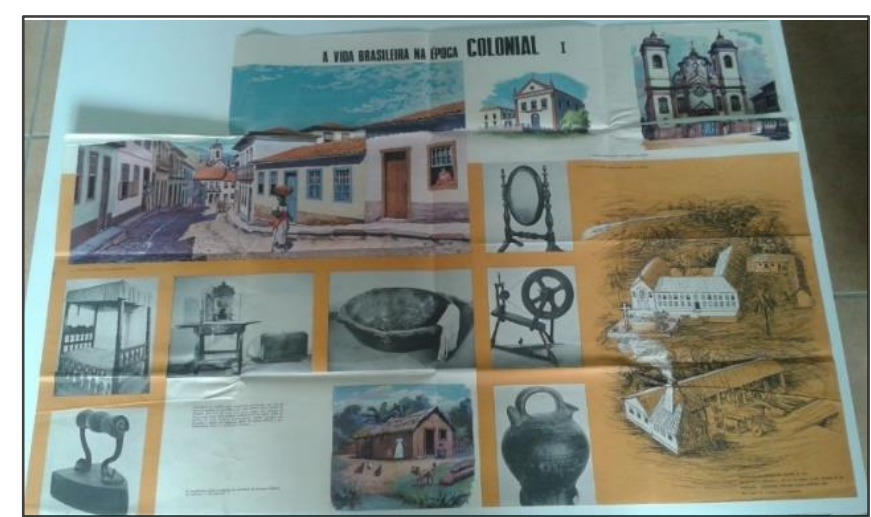

Fonte: Revista do Ensino/RS, nº124, 1969. Acervo: Hisales/UFPel-Pelotas/RS

13 Este suplemento foi elaborado pela equipe: Orientação e Lay-out: Magdalena Lutzemberger; Planejamento: Cláudia Strauss e Maria Aparecida Grendene; Desenhos: Carl Ernest Zeuner e Nilza Graus Haertel. 
Toda a série Vida no - Litoral (n²9), Campo (n³0), Mata (n³1?), Sertão (nº7), Cidade ( $\left.{ }^{\circ} 98\right)$, Serra ( $\left.{ }^{\circ} 99\right)$-, pelos quadros presentes no Acervo do Margs, é expressiva pela quantidade de pequenas gravuras, com riqueza de detalhes e cores. Localizamos somente o suplemento "A Vida na Mata" (Figura 5), que possibilita explicitar a quantidade de pequenos quadros, totalizando 17. Desse quadro, podemos identificar que 14 gravuras foram realizadas pelo Zeuner. Três imagens são de bichos que se encontram nesse habitat: animais, pássaros e répteis, cuja imagens podem ter sido retirados de livros para completar o suplemento.

Figura 5: A Vida na Mata

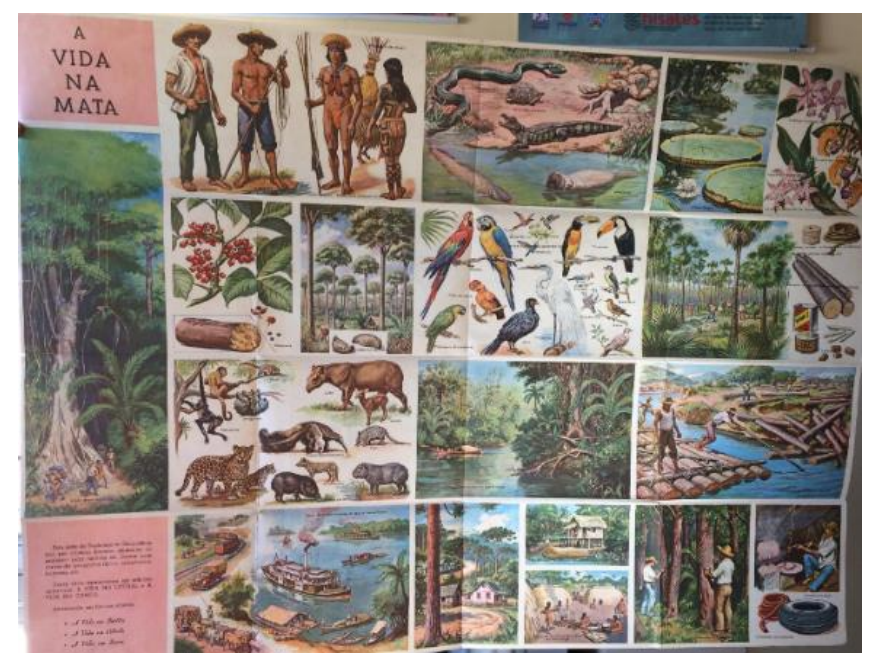

Fonte: Hisales/UFPel-Pelotas/RS

Entre as várias gravuras, optamos por analisar aquelas que consideramos mais representativas do universo da escola. $\mathrm{O}$ conjunto selecionado se refere às festas escolares, ao longo do ano letivo, as quais podem ser classificadas como eventos cívicos, religiosos e sociais ${ }^{14}$. Para Rodrigues (2010, p.97), "as festas contribuem para a constituição de um modo de construir e difundir referências e símbolos nacionais, integrando a memória coletiva nacional".

O conjunto "Principais Comemorações do Ano I" (RE/RS, n¹10, 1966) apresenta gravuras alusivas ao Natal, Dia das Mães, Páscoa e Festas Juninas; e "Principais Comemorações do Ano II" (RE/RS, n¹14, 1967) elenca as festas do segundo semestre do ano letivo, com exceção do Natal, com gravuras alusivas ao Dia da Árvore, Dia do Trabalho, Dia do Papai e Semana da Pátria. A orientação "Como aproveitar o suplemento" assinala:

As gravuras que fazem parte deste suplemento poderão ser apresentadas como incentivo para o desenvolvimento de unidades relativas às datas em destaque. Servirão, também, como motivo para a realização de composições, orais e escritas. Tais composições, conforme o adiantamento da classe, poderão constar de enumeração de elementos da gravura; elaboração de sentenças, mencionando os personagens, os fatos, as ações principais; elaboração de contos, estórias e poesias. Os alunos poderão, ainda, relatar experiências próprias relacionadas ao conteúdo das gravuras

\footnotetext{
${ }^{14}$ Sobre, ver Jacques (2015); Chanon (2002).
} 
e coletar músicas e poesias referente a essas comemorações. Deve o professor levar os alunos a sentirem o espírito cristão de datas como o Natal e a Páscoa, lembrando que festas e presentes são formas de demonstrar alegria pelos acontecimentos religiosos e não a razão primordial das mesmas. (RE/RS, $\left.\mathrm{n}^{\circ} 144,1967\right)$

A recomendação dada era que as duas festas - Natal e Páscoa - deveriam ser exaltadas como comemorações religiosas, nas quais seria enfatizado o espírito cristão e não o comercial. No corpo do periódico havia inúmeras orientações detalhadas para cada comemoração, envolvendo a organização da programação, textos e atividades para as diferentes disciplinas, tanto para o professor como para os alunos, músicas, dramatizações, desenhos, recortes.

O ano letivo escolar inicia com a Festa da Páscoa, desenhada por Zeuner através de uma atividade de preparação à festa em uma sala de aula, conforme a figura abaixo.

Figura 6: Festa da Páscoa. Desenho de Carl Ernest Zeuner.

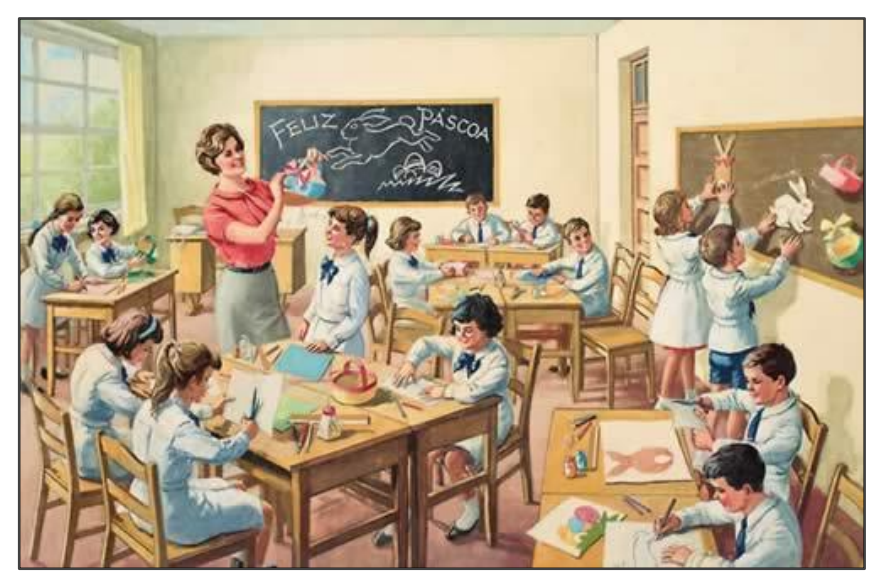

Fonte: Margs. Suplemento da Revista do Ensino/RS, nº110, 1966.

A gravura expressa, com preciosidade de detalhes, uma sala de aula do ensino primário de um grupo escolar da rede pública. Essa constatação se apoia no vestuário das crianças: uniforme adotado pelo Estado e obrigatório para os grupos escolares - composto de guarda pó branco, laço ou gravata azul marinho. A sala apresenta quadro negro, mesa e cadeira para a professora, quatorze mesas e cadeiras para os alunos, oito meninas e seis meninos. Estas estão organizadas em duplas e/ou grupos de quatro. A atividade é de desenhar e recortar motivos relativos à festa da Páscoa (coelhinhos, ovos, confecção de cestinhas), para a decoração da sala e do quadro mural. Sobre as mesas há materiais diversos: cartolina, tesoura, tintas, lápis de cor. No quadro negro está escrito "Feliz Páscoa" e desenhado um coelhinho e os ovos sob uma pequena relva. A professora primária está interagindo com as alunas de um grupo e analisando a cestinha para os ovos, provavelmente confeccionada pela aluna que está de pé. Um menino e uma menina prendem desenhos no quadro mural - uma cara de coelho estilizada e um coelho, no qual já consta um grande ovo, um cesto. O coelho pregado é similar ao modelo presente na revista e desenhado no quadro negro, o que podemos inferir que foi reproduzido para os alunos o traçado, tão somente, para colorirem e cortarem. A imagem idealiza uma sala de aula harmônica e tranquila, com interação entre alunos e a professora, que podemos pensar elegantemente vestida para os padrões da época (década de 1960), considerada os "anos dourados" da professora riograndense (FISCHER, 2005). 
O Dia do Trabalho é um feriado mundial, comemorado sempre no dia primeiro de maio. Hoje, são poucas instituições escolares que comemoram esse dia. No entanto, nos anos 1960 parece compor o calendário de festas ou temas escolares, como na figura abaixo.

Figura 7: Dia do Trabalho. Desenho de Carl Ernest Zeuner

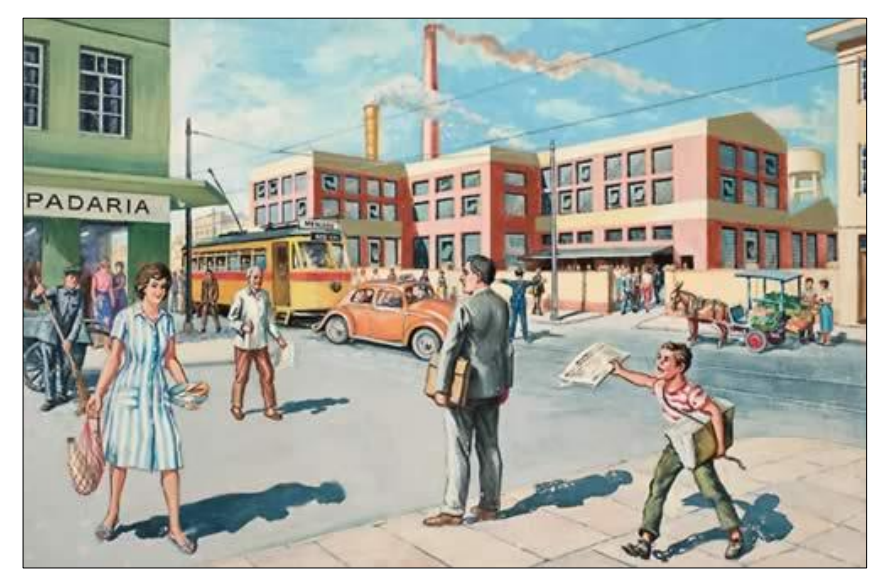

Fonte: Margs. Suplemento da Revista do Ensino/RS, nº110, 1966.

A gravura registra uma cena de contexto urbano, com destaque de uma indústria ou fábrica, o prédio da padaria, um bonde, um automóvel da marca Volkswagem. As pessoas que transitam, que estão compondo a paisagem, são os operários saindo da fábrica, o guarda de trânsito, o verdureiro com sua carroça e seus produtos, um varredor de rua uniformizado. Em primeiro plano, uma senhora com suas compras, um senhor de terno e pasta, esperando para atravessar a rua, e, em destaque, um menino que exerce a função de jornaleiro mirim, isto é, um trabalho infantil para meninos carentes ${ }^{15}$. Esse conjunto visava mostrar às crianças as diferentes atividades desenvolvidas pelo homem, das mais diversas profissões em centros urbanos, com o objetivo de "levar a criança a perceber que todas elas são úteis e necessárias à comunidade, merecendo, portanto, todo nosso respeito" (RE/RS, nº114, 1967, p.64).

A imagem 8, abaixo, integra esse primeiro quadro, que contêm mais sete imagens vinculadas à indústria do vinho e da madeira, produtos de utilidade e conforto, matéria prima, produtos de transformação. O segundo suplemento tem como subtítulo "A indústria também contribui para a segurança nacional", adequando-se à preocupação central da Ditadura Militar, implantada em 1964. O quadro é composto de 11 imagens, as quais são destacadas por títulos: produtos de utilidade e conforto, fornecendo energia, produtos alimentares, indústria do papel, fabricando peças que facilitem o transporte, produzindo metais, construindo veículos de transporte e defesa, facilitando a comunicação. O terceiro suplemento traz somente o título "O trabalho humano e as indústrias brasileiras", contendo 15 imagens O objetivo desses três quadros é colocar em "evidência nos dias atuais a atividade industrial", que o professor poderá explorar em diferentes disciplinas (linguagem, matemática, estudos sociais), agrupando por regiões brasileiras e finalidades. Por exemplo, indústrias destinadas à

\footnotetext{
15 Em 1940, a esposa de Getúlio Vargas, Dona Darcy Vargas, cria a Casa do Pequeno Jornaleiro, para dar assistência aos menores de idade. Braço da Fundação Darcy Vargas, a CPJ se propunha a abrigar os jovens jornaleiros e ampará-los em seu ciclo educacional, oferecendo ensino profissionalizante e atividades de lazer. [http://www.fdv.org.br/fundadora.asp]. Nos anos 1960, a Ação Social São Vicente de Paulo - Irmãs Vicentinas ofereciam Curso de Jornaleiro para pequenos grupos de meninos que buscavam ocupações e uma forma de sustento para auxiliar as famílias. Sobre as representações sociais do pequeno jornaleiro, nas décadas de 1930 e 1940, que, em certa medida, culminaram na construção de soluções filantrópicas, como a Casa do Pequeno Jornaleiro, ver Chagas (2013).
} 
alimentação, ao vestuário, ao transporte e outras. Esses dois últimos suplementos diferem dos demais, pois destacam as imagens com pequenos títulos, direcionando o olhar do aluno.

Figura 8: O trabalho humano, indústria brasileira: Aspectos da zona industrial de uma cidade.

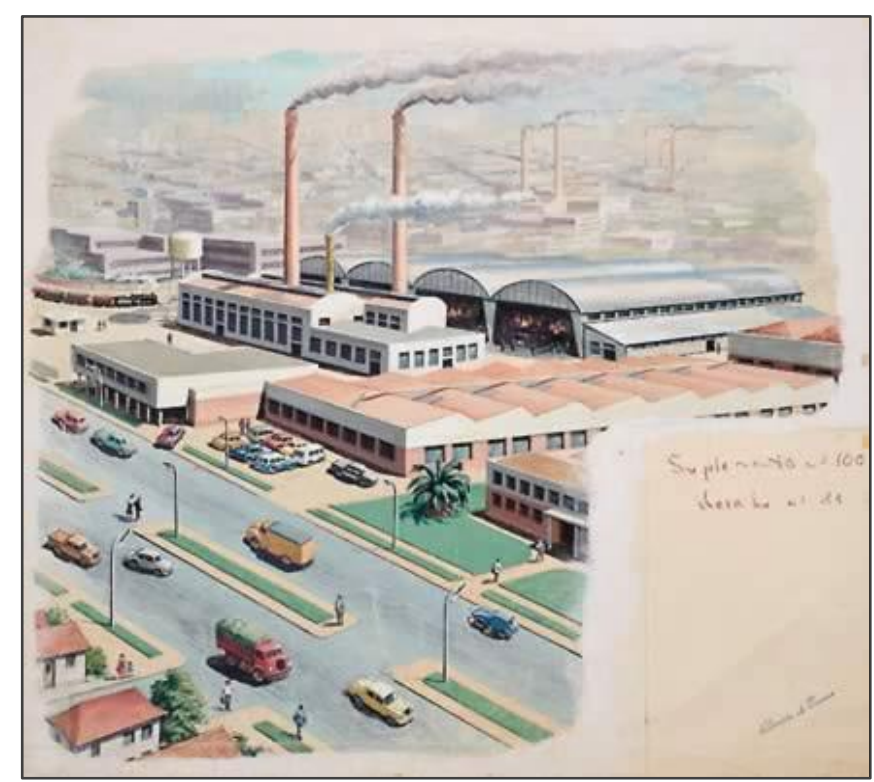

Fonte: MARGS. Desenho de Carl Ernest Zeuner (RE/RS, nº100, 1965)

Na série "A vida na Cidade", também observamos que Zeuner procurou retratar inúmeros profissionais, identificados como "servidores da comunidade", buscando traduzir ao aluno a importância do trabalho. Nas figuras 9 e 10, abaixo, a imagem apresenta, em primeiro plano, um guarda de trânsito orientando a travessia das crianças do Grupo escolar, com outras crianças à direita da imagem. Esse quadro permite observar a preocupação do desenhista em aproximar sua representação gráfica do cotidiano da escola.

Figura 9 e 10: Servidores da comunidade (1963-1969)

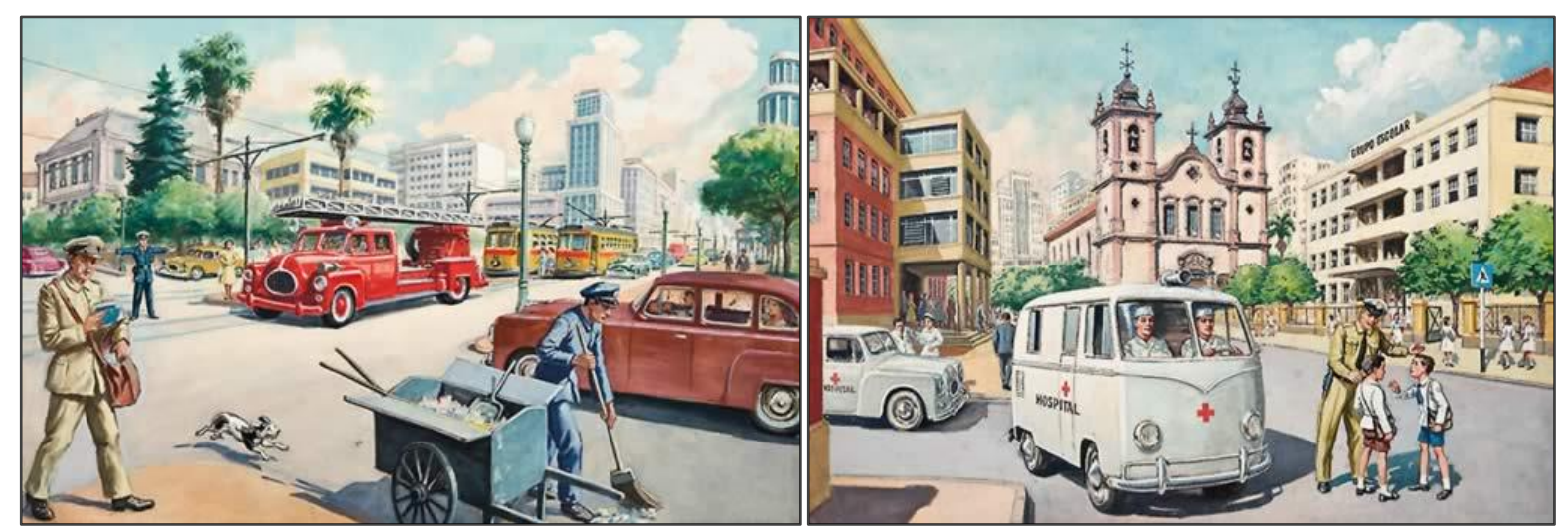

Fonte: Margs

O dia das Mães, comemorado no segundo domingo de maio, é representado no ambiente privado e doméstico do lar, com uma família nuclear de classe média (pai, mãe e três filhos), todos sorridentes. O filho menor entrega flores para a mãe. A mesa posta para comemorarem o dia, com torta e refrigerante, que são trazidos pelo pai, trajado socialmente de camisa e gravata, o que denota um padrão formal no cotidiano. Para 
Burke (2004, p.109), as pinturas de interiores domésticos devem ser problematizadas quanto ao que se deve ou não ser mostrado. Nessa perspectiva, o ambiente desenhado revela uma harmonia que não necessariamente corresponde às famílias dos estudantes de escola pública, aos quais se destinavam.

Figura 11: Dia das Mães. Desenho de Carl Ernest Zeuner

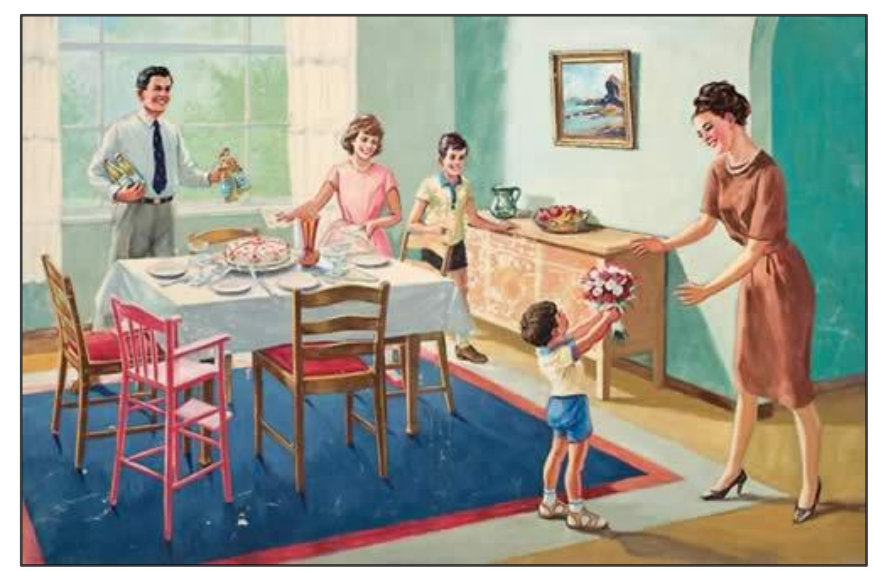

Fonte: Margs. Suplemento da Revista do Ensino/RS, nº110, 1966.

Para representar a festa Junina, comemorada no dia de São João (24 de junho, considerada a noite mais longa do ano), o cenário escolhido por Zeuner foi destacar os folguedos em torno da fogueira, onde todos estão caracterizados de "caipiras". No fundo, a imagem traz adultos e uma grande mesa com guloseimas. Sentado no banco de uma mesa, está um menino tocando acordeão. O espaço parece sinalizar um local público e amplo, não necessariamente um pátio de escola.

Figura 12. Festa Junina. Desenho de Carl Ernest Zeuner

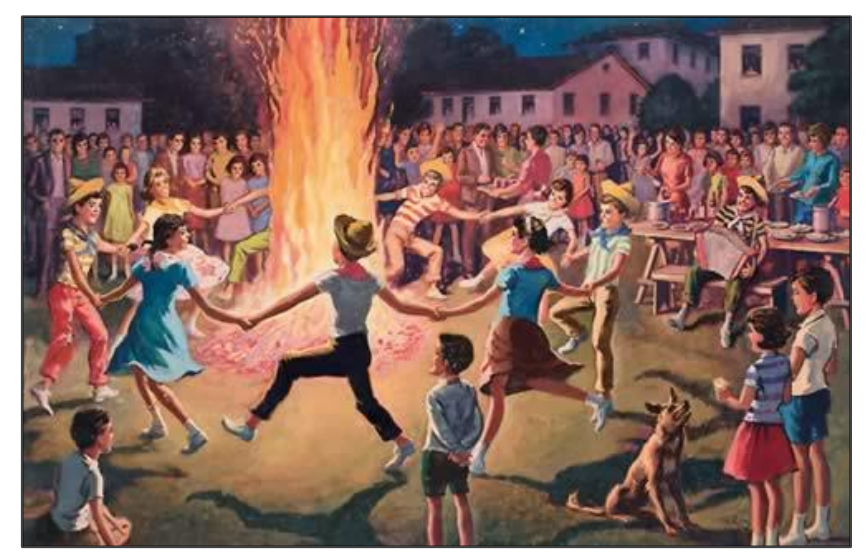

Fonte: Margs. Suplemento da Revista do Ensino/RS, nº110, 1966.

O suplemento "Principais comemorações do Ano II" (RE/RS, n¹14, 1967, p.64), com as gravuras alusivas ao Dia do Trabalho, da Árvore, Dia do Papai e Semana da Pátria, recomenda como atividades a elaboração de "composições orais e escritas, contos, estórias e poesias", que, conforme o adiantamento da classe, poderão constar de "enumeração de elementos da gravura; elaboração de sentenças, mencionando os personagens, os fatos e as ações principais"

O Dia dos Pais, identificado com o diminutivo "papai", comemorado no segundo domingo de agosto, registra o momento familiar, pela manhã, em que as crianças, ainda de pijama, levam seus presentes ao pai, que está sentado em uma poltrona, lendo o jornal. A 
mãe espia a cena da porta da sala. É interessante observar que, diferentemente do Dia das Mães, a revista publica muito poucos textos, músicas, poesias e atividades relativas à data. Podemos pensar que o pai, como provedor da família, não estava disponível para as atividades escolares, ou que fosse considerada uma data menor decorrente do destaque da Igreja Católica à figura de Maria em relação à mãe.

Figura 13: O Dia do Papai. Desenho de Carl Ernest Zeuner

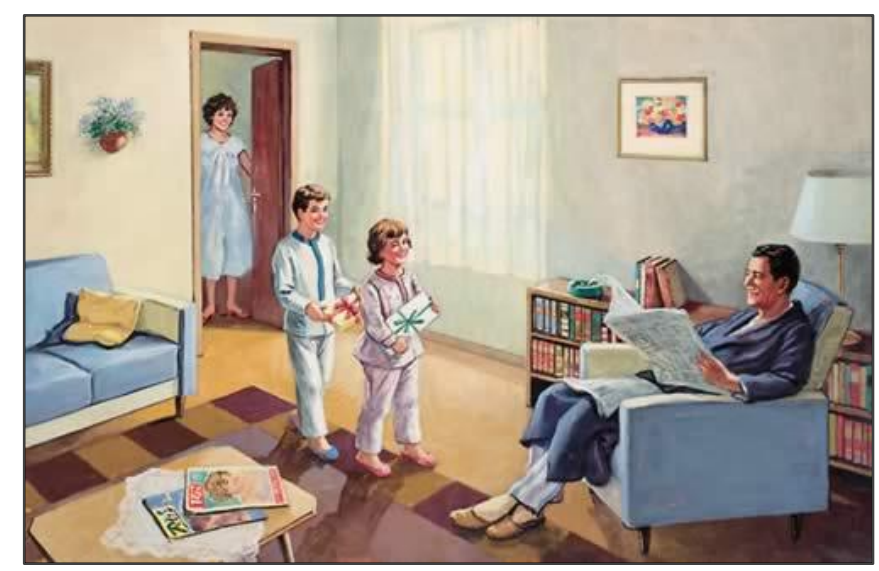

Fonte: Margs.

O quadro mural relativo à Semana da Pátria ${ }^{16}$ representa o desfile da Juventude no Sete de Setembro, em frente à Pira da Pátria, na época junto ao Parque da Redenção e a Avenida João Pessoa, em Porto Alegre/RS. Em primeiro plano, alunos do ensino secundário - ginásio e médio. Meninas seguidas pelos meninos, ambos uniformizados e portando a bandeira nacional, passando em frente da Pira da Pátria, onde se encontram famílias com crianças. Ao fundo, se percebe um grande público assistindo e estudantes desfilando.

Figura 14: Semana da Pátria. Desenho de Carl Ernest Zeuner.

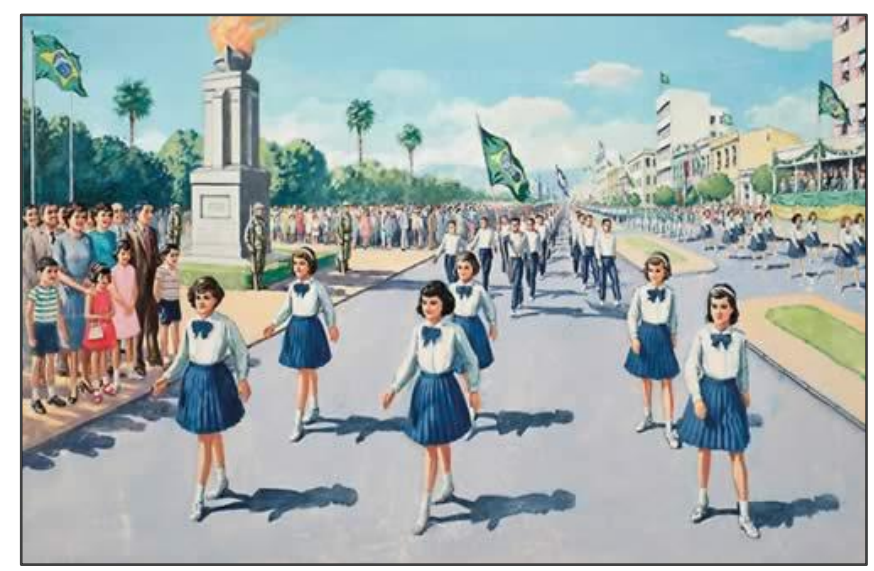

Fonte: Margs

Em diversos números do periódico são dadas orientações oficiais para essa data. No número 107, de 1966, é publicado o Comunicado e ofícios circulares do CPOE/RS para a Semana da Pátria, com o plano de atividades para essa semana, o que incluía explicar aos alunos "porque comemorar a semana da Pátria".

\footnotetext{
${ }^{16}$ Sobre os desfiles patrióticos, ver Bencostta (2005)
} 
A imagem desenhada para a Festa ou o Dia da Árvore ${ }^{17}$, comemorado em 21 de setembro, apresenta o plantio de uma árvore, por dois jovens, no jardim de uma casa (Figura 15), o que permite depreender um objetivo de estimular uma atitude e/ou uma "consciência ecológica", conforme Rodrigues (2010, p. 119). As atividades recomendadas para essa festa buscavam enfatizar o valor da arborização da cidade, tanto pelo aspecto estético como pela "renovação do ar".

No número 106, de 1965 (p.63-64), a orientação para explorar essa data recomenda estudos sobre a árvore em "seus aspectos nas diferentes estações do ano e suas partes", mas também os diferentes materiais que a árvore oferece ao homem. Acentua que é interessante levar o aluno "à consciência de que para o homem antigo [a árvore] foi a maior fonte de materiais" para a vida. Também sugere que, além da madeira, enfatize que a casca e as folhas das árvores são utilizadas para a fabricação de tintas e fibras, do papel, e fonte de alimentos para o homem. Como atividade externa à escola, são recomendadas visitas dos alunos a uma fábrica de móveis.

Figura 15: Dia da Árvore. Desenho de Carl Ernest Zeuner.

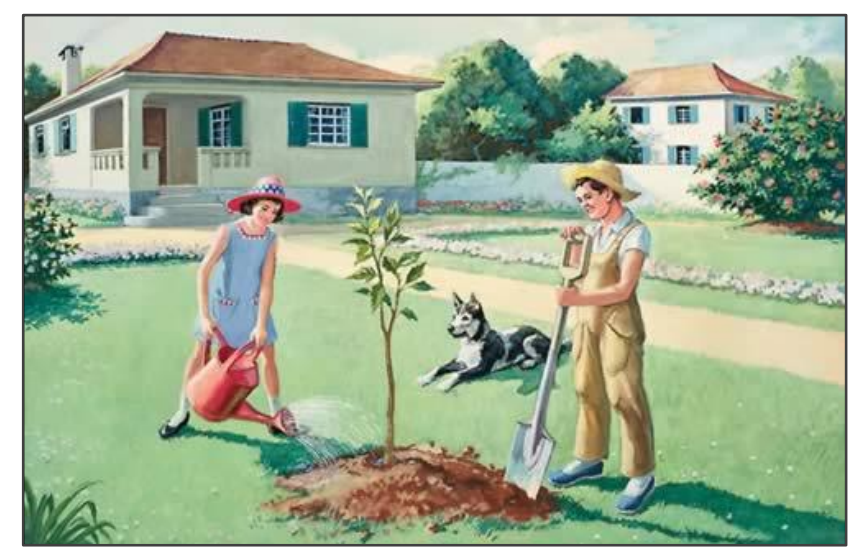

Fonte: Acervo: Margs

O Natal na figura abaixo, é identificado como uma "das principais comemorações do ano de uma cidade". Em dezembro, o término das aulas, provas e exames, culminam com a entrega final das avaliações e preparação do espírito Natalino. Nesse sentido, o periódico traz um número significativo de atividades, músicas, poesias relativas à essa data. Zeuner retrata essa data novamente em um ambiente doméstico, em que a família está envolvida com a decoração natalina: o pai envolvido com a decoração do pinheiro, a mãe e a filha com a arrumação do presépio. Um pequeno detalhe de um quadro na parede, ao lado do ponto de luz, que reproduz a imagem de uma santa, evidencia que a família é católica. No entanto, a comemoração do Natal envolve também outros credos religiosos.

\footnotetext{
${ }^{17}$ Para Rodrigues (2010, p.98-99), a festa da árvore foi uma das festas cívicas estimuladas pela Revolução Francesa. No entanto, assinala que várias culturas muito antigas já tinham o culto das árvores e florestas. As árvores são símbolos de verticalidade, de transformação e evolução, da vida, da fecundidade e fertilidade, da segurança e de proteção. Citando Nona Ozouf, "a árvore é um educador, o silêncio pedagogo da comunidade".
} 
Figura 16: Principais comemorações do ano de uma cidade: Natal.

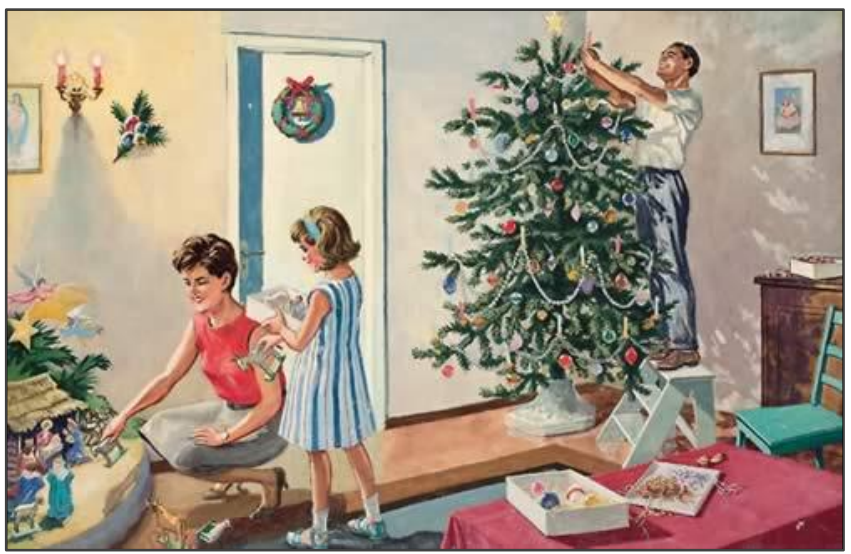

Fonte: Desenho de Carl Ernest Zeuner. Acervo: Margs

\section{PALAVRAS FINAIS}

As imagens aqui analisadas expressam a leitura de um ilustrador na criação de dispositivos didáticos para uso da sala de aula da escola primária. As paisagens desenhadas representam uma imagem idealizada de uma realidade que não correspondia a da maioria dos alunos da escola pública da época. O significado desse conjunto, desenhado por Zeuner e publicado em suplementos didáticos, deve ser analisado a partir do seu "contexto social" e de sua intenção precípua (BURKE, 2004, p.225). Foram desenhadas para "persuadir ou obrigar estudantes a fazer determinadas interpretações", conforme as orientações fornecidas pelo periódico.

$\mathrm{O}$ estudo da imagem como um arquivo da memória escolar e das práticas educativas é um dispositivo de (in)formação. A Revista do Ensino/RS, ao fazer uso intensivo da iconografia em sua produção editorial, visava vulgarizar os recursos visuais em sala de aula e organizar o currículo escolar não como uma simples representação da "realidade", mas sim em um amplo sistema simbólico (SAMAIN, 1996). Assim, o processo de alfabetização da escola primária também envolvia uma alfabetização visual, como fonte de conhecimento e inteligência. A imagem deveria impregnar a alma infantil, como mais um dispositivo produtor de mensagens didático-pedagógicas.

Na perspectiva da escola nova, aprender a ver é condição essencial às atividades de experimentação. Assim, a pedagogia pela imagem ou em imagens busca uma "didatização" do olhar, sacralizando uma representação de uma dada realidade limitada ao conteúdo manifesto, tendo em vista a minuciosa orientação para sua exploração pelo professor, tirando a possibilidade de outras visões e interpretações possíveis.

A leitura iconográfica, como atividade educacional, desenvolve o olhar crítico, ensina a aprender a ver o mundo e a organizar a experiência, produzindo sentido às imagens (MARTELLI, 2003). A imagem não atua como uma mera ilustração, mas exerce uma função formativa do imaginário social, importante veículo de aculturação do sujeito, perpetua identidades, valores, tradições, culturas.

O ensino pelos sentidos e a educação para a aprendizagem dos sentidos marca de forma significativa a primazia da observação sobre a experimentação nas práticas escolares. O ensino da leitura, da história e da geografia, a formação - moral, cívica, religiosa e patriótica - estavam presentes nos quadros de Zeuner. Feldman (2004, p. 94) destaca a função educativa das imagens na sala de aula: representam o mundo segundo padrões relacionados com a moralidade, a praticidade e a pátria; representam a realidade 
de forma estereotipada e idealizada, ordenando-o e simplificando-o; impõem uma ordem coincidente com o padrão do currículo.

O estudo das imagens - cartazes de propaganda, anúncios de publicidade, ilustração de livros didáticos e revistas pedagógicas, fotografias, mapas, plantas, filmes, lâminas, slides, obras de arte, desenhos, histórias em quadrinhos, etc. - oferece múltiplas possibilidades de leitura da cultura escolar, como discurso pedagógico e não como um mero elemento decorativo.

A iconografia em sala de aula, em suportes variados, é um tema atual e merece ser foco de atenção dos educadores, em criarem situações para os alunos refletirem sobre as imagens temporalizadas, em uma sociedade cada vez mais dominada pelas imagens da mídia.

\section{REFERÊNCIAS}

BASTOS, M.H.C. A Revista do Ensino do Rio Grande do Sul (1939-1942). O Novo e o Nacional em revista. Pelotas: Seiva Publicações, 2005. https://doi.org/10.1590/s0101$\underline{81082005000300014}$

BASTOS, M.H.C. As revistas pedagógicas e a atualização do professor: A Revista do Ensino do Rio Grande do Sul (1951-1992). In: CATANI, D.; BASTOS, M.H.C. (Org.). Educação em Revista. A Imprensa periódica e a História da Educação. São Paulo: Escrituras, 1997. P. 47 a 76. https://doi.org/10.1590/s0101-81082007000200004

BASTOS, M.H.C. Imprensa pedagógica rio-grandense: CACIQUE - a revista da garotada gaúcha (1954-1963). Educação. PUC/RS Porto Alegre, v. XVII, n. 27, p.85-100, 1994.

BASTOS, M.H.C.; BUSNELlO, Fernanda. Pedagogia em Imagens. A Revista do Ensino/RS : entre discursos e imagens (1951-1978). In : Anais do V ANPED Sul. Seminário de Pesquisa em Educação da Região Sul. Pesquisa em Educação e Compromisso Social. Curitiba/PR, PUCPr, 2004. (Cdrom). https://doi.org/10.5151/sosci-xisepech-gt6_121

BASTOS, M.H.C.; LEMOS, Elizandra A. Uma iconografia da cultura escolar: a Revista do Ensino/RS (1951-1978). In: ARAÚJO, José Carlos; SCHELBAEUR, Analete R. (Org.) A imprensa como objeto histórico-educacional: metodologias e abordagens. Campinas/SP: Autores Associados, 2006.

BASTOS, M.H.C.; LEMOS, Elizandra Ambrósio; BUSNELLO, Fernanda Bastani (2007). A pedagogia da ilustração: uma face do impresso. In: BENCOSTTA, Marcus Levy Albino (org.) Culturas escolares, saberes e práticas educativas. Itinerários históricos. 1ed.São Paulo: Cortez Editora, 2007, v. 1, p. 41-78.

BENCOSTTA, Marcus Levy Albino. Desfiles patrióticos: Memória e cultura cívica dos grupos escolares de Curitiba (1903-1971). In: VIDAL, Diana Gonçalves. Grupos Escolares: cultura escolar primária e escolarização da infância no Brasil (1893-1971). Campinas: Mercado de Letras, 2005. https://doi.org/10.1590/0104-4060.236

BENCOSTTA, Marcus Levy Albino. Imagem e História: As Fotografias Escolares no Estudo da Escola Primária Curitibana (1903-1971). In: Anais do XXII Simpósio Nacional de História. João Pessoa: UFPB/ANPUH, julho de 2003, p. 10-25. https://doi.org/10.1590/s0101$\underline{90742011000100019}$ 
BITTENCOURT, Circe. Livros didáticos entre textos e imagens. In: BITTENCOURT, Circe (Org.). O saber histórico na sala de aula. São Paulo: Contexto. 2002. pp.69-90.

BURKE, Peter. Testemunha Ocular. História e Imagem. Bauru: EDUSC, 2004.

CHAGAS, Viktor. EXTRA! EXTRA! Os jornaleiros e as bancas de jornais como espaço de disputas pelo controle da distribuição da imprensa e da economia política dos meios. Rio de Janeiro: FGV-CPDOC, 2013. Tese de Doutorado em História, Política e Bens culturais. file:///C:/Users/mbastos/Downloads/TESE-FINAL-final\%C3\%ADssima-finalmente-

\%C3\%BAltima_forma-vers\%C3\%A3o_mais_recente-absoluta-enfim-2\%20(1).pdf. Acessado em 3 de abril de 2017. https://doi.org/10.12660/rm.v4n7.2013.62805

CHALMEL, Loic. Imagens de crianças e crianças nas imagens: representações da infância na iconografia pedagógica nos séculos XIX e XX. Educação \& Sociedade. Campinas, vol. 25, n. 86, p. 57-74, abril 2004. https://doi.org/10.1590/s0101-73302004000100005

CHAMON, Carla Simone. Festejos Imperiais: Festas Cívicas em Minas Gerais (1815-1845). Bragança Paulista/SP: EDUSF, 2002.

CHARTIER, Roger. As utilizações do objecto impresso. Portugal, DIFEL, 1998.

FELDMAN, Daniel. Imágeneas en la historia de la enseñanza: la lámina escolar. Educação \& Sociedade. Campinas, vol. 25, n. 86, p. 75-101, abril 2004. https://doi.org/10.1590/s0101$\underline{73302004000100006}$

FERREIRA, Marieta de M.; KORNIS, Mônica A. Entrevista com Phillippe Dubois. Estudos Históricos. Rio de Janeiro, n³4, jul-dez. 2004pp.139-156.

FISCHER, Beatriz T. Daudt. Professoras: Histórias e Discursos de um Passado Presente. Pelotas: Seiva, 2005.

GARCIA, Fabiane Fernandes; PERES, Eliane. Leituras de formação docente: produção e circulação de obras pedagógicas no Rio Grande do Sul (1869-1970). In: Anais do VIII Encontro Sul-rio-grandense de pesquisadores em História da Educação. Iconografia e Pesquisa Histórica. Gramado: ASPHE, 2002. pp. 97-104. https://doi.org/10.5327/z0375$\underline{75362012000200010}$

GOMES, Leonardo Menna Barreto. Ernest Zeuner: artista e designer. Porto Alegre: PUCRS. 2001. 296f. Dissertação de Mestrado do Programa de Pós-graduação da Faculdade de Comunicação Social. https://doi.org/10.18226/610001/mostraxvi.2016.45

HALLEWELL, Laurence. O Livro no Brasil: História. São Paulo: EDUSP, 2005.

JACQUES, Alice Rigoni. O Ensino Primário no Colégio Farroupilha: Da Nacionalização do Ensino à LDB No 4.024 (Porto Alegre/ RS: 1937/1961). Porto Alegre: PPGE-PUCRS, 2015. Tese de Doutorado em Educação (Programa de Pós-Graduação em Educação Pontifícia Universidade Católica do Rio Grande do Sul). https://doi.org/10.19070/2572-7354-160006 
JODELET, Denise. Representações sociais: um domínio em expansão. In: JODELET, Denise (Org.). As representações sociais. Rio de Janeiro: EdUERJ, 2001. p. 17-44. https://doi.org/10.17771/pucrio.acad.16772

MÁRQUEZ, Gabriel García. [1997] 2011. Garrafa ao mar para o Deus das palavras. In: MÁRQUEZ, Gabriel G. Eu não vim fazer discurso. Rio de Janeiro: Record. p. 101-103.

MARTELLI, Josyanne Milléo. O Uso da Imagem na Pesquisa Educacional. In: Anais da XXVI Reunião Anual da ANPED. Novo Governo, nova política. O papel histórico da ANPED na produção de políticas educacionais. Poços de Caldas/MG, 5 a 8 de outubro de 2003. (CDRom) 23p. https://doi.org/10.5380/jpe.v11i0.54624

PERES, Eliane T. A Escola Ativa na visão de Adolphe Ferrière - Elementos para compreender a Escola Nova no Brasil. In: STEPHANOU, M.; BASTOS, M.H.C (Org.) Histórias e Memórias da Educação no Brasil. Petrópolis: Vozes, 2005. Volume III, pp. 114-128.

PERES, Eliane T. Aprendendo formas de pensar, de sentir e de agir - a escola como oficina da vida: discursos pedagógicos e práticas escolares da escola pública primária gaúcha (19091959). Belo Horizonte: UFMG, 2000. Tese (Doutorado em Educação). https://doi.org/10.17648/galoa-cbee-6-30656

QUADROS, Claudemir. Centro de pesquisas e Orientação Educacional - CPOE/RS: discursos e ações institucionais. Porto Alegre: UFRGS, 2005. Projeto de Tese (Doutorado em Educação)

RAMOS, Paula. A Modernidade impressa. Artistas Ilustradores da Livraria do Globo - Porto Alegre. Porto Alegre/RS: UFRGS Editora, 2016. https://doi.org/10.17140/oroj-3-124

RENONCIAT, Annie (Dir.). Voir/Savoir. La pédagogie para l'image aux temps de l'imprimé (du XVI au XIX siècle). Paris: CNDP-CRDP, 2011.

REVISTA do Ensino. Análise e sugestões. São Paulo/Porto Alegre, 20 de fevereiro de 1978. (mimeo)

RODRIGUES, Maria Manuela P.F. Festas escolares: as festas da árvore no Barreiro. História da Educação/ASPHE, v.14, n.31, p. 95-119, maio/ago 2010.

SOUZA, Rosa Fátima. Fotografias escolares: a leitura de imagens na história da escola primária. Educar em Revista. Curitiba/PR, no18. 2001. pp.75-101. https://doi.org/10.1590/0104-4060.235

TORRESINI, Elizabeth Wendhausen Rochadel. Editora Globo: uma aventura editorial nos anos 30 e 40. Porto Alegre: Editora Globo, 1998.

SCARINCI, Carlos. A Gravura no Rio Grande do Sul (1900-1980). Porto Alegre: Mercado Aberto, 1982. 